\title{
COVID-19 INSIGHTS AND LINGUISTIC METHODS
}

\author{
KIM HUA TAN $^{1 *}$, PETER WOODS ${ }^{2}$, HAZITA AZMAN ${ }^{1}$, IMRAN HO ABDULLAH ${ }^{1}$, RUZY SULIZA \\ HASHIM $^{1}$, HAJAR ABDUL RAHIM ${ }^{3}$, MOHD MUZHAFAR IDRUS ${ }^{4}$, NUR EHSAN MOHD SAID ${ }^{5}$, ROBERT \\ LEW $^{6}$, IZTOK KOSEM ${ }^{7}$
}

${ }^{1}$ Faculty of Social Sciences \& Humanities, Universiti Kebangsaan Malaysia

${ }^{2}$ Knowledge Management Centre, Faculty of Creative Multimedia, Multimedia University, Malaysia

${ }^{3}$ School of Humanities, Universiti Sains Malaysia

${ }^{4}$ Faculty of Major Language Studies, Universiti Sains Islam Malaysia

${ }^{5}$ Faculty of Education, Universiti Kebangsan Malaysia

${ }^{6}$ Faculty of English, Adam Mickiewicz University, Poznań, Poland

${ }^{7}$ Jožef Stefan Institute \& University of Ljubljana, Slovenia

kimmy@ukm.edu.my

\begin{abstract}
The emergence of COVID-19 affects the world population in many ways, resulting in its own specialised discourse. In addition to providing a source of data for analysis, this discourse has also led to a rethinking of multifarious research methods. This section presents a series of articles by scholars from different parts of the world with macro- and micro-linguistic perspectives, ranging from corpus-based analysis to content analysis studies. At the macro level, these scholars explored ways through which government bodies communicate with the public. Official announcements, parliamentary proceedings and COVID-19-related corpora are examined and a comparative textual analysis between the Malaysian and British governments is provided. At the micro level, the scholars analysed selected corpora with lexical, semantic, and discourse foci and personal posts of short narratives and photos to encapsulate meanings from human life and experience. The main takeaway from these studies is the application of a wide range of methods for different focus and perspectives that may be customised to the researcher's unique context.
\end{abstract}

Keywords: COVID-19, corpus-based approach, comparative textual analysis, qualitative content analysis, lexical neologism 
'FEAR' IN COVID-19 FAKE NEWS: A CORPUS-BASED APPROACH

Kim Hua, Tan

\section{CONTEXTUAL BACKGROUND}

In the wake of the coronavirus pandemic, the World Health Organisation has warned against a tsunami of disinformation or 'infodemic'. Every second, people are bombarded with COVID19 information, some of which may be false (Hua \& Shaw, 2020). Massive amounts of information and data are being released and shared at a scale that has never been seen before. This phenomenon has become a new challenge as Covid-19 spreads fast around the world.

Most studies on fake news focus on the psychological effects of COVID-19 or highlight the message or content disinformation only, while paying less attention to journalistic style and language. Fake news appears similar to real news in form but lacks the rigour of good writing practice. The intention of fake news is not to ensure the accuracy and credibility of the information but to spread falsehood to achieve malicious purposes. Therefore, news verification is crucial. Most verification procedures for fake news are slow and sourced from intermediary bodies such as Google and Snopes. The rapid spread of disinformation through social media necessitates a reliable self- verification tool that readers can use during emergency situations. The next best approach is to educate the public on the characteristics, particularly the linguistic features, of fake news.

Limited information is known about the linguistic mechanisms underlying fake news.

\section{METHODOLOGY}

Some linguistic features that can be examined are recurring verbs or content words in the texts. A comparison of these verbs or or content words in the form of noun premodification types (Ang, Tan \& He, 2017) in a content-parallel corpora of real and fake news is another possibility. Examining an entity such as 'FEAR' and its linguistic realisations is interesting (Mertens, Gerritsen, Salemink, \& Engelhard. 2020) as 'fear' is prevalent in such news. People have scarce knowledge of how linguistic items acquire 'FEAR' associations or how metaphors of 'FEAR' are used. I will illustrate the investigation of the propagation of FEAR constructs and their associations in fake news.

The objectives of this study are to:

1. identify the constructs and associations of 'FEAR' in fake news, and

2. define fake news and differentiate them from real news.

This study adopts a corpus-based methodology where corpus development, analysis and interpretation are necessary steps.

THE CORPORA

The goal of this study is to investigate the linguistic properties of fake news from corpora obtained from Snopes.com, FactCheck.org, TurnBackHoax.id and Google Fact Check. The contents or messages are already flagged as fake news in go-to-source internet links.

Suggested corpora attributes:

a) Local (Malaysian), overseas (e.g. news from overseas as reported by Reuters)

b) Period of 10 days when the fake news peaked: a) 13th - 22nd March, b) 23rd March 5th April, c) 6th - 19th April, and d) 20th - 30th April

d) Proposed Thematic content: i) spread of COVID-19, ii) conspiracy theories, and iii) cases of contracting COVID-19 (world leaders, celebrities, health workers)

e) Social media platforms: Twitter, Instagram and Facebook 
Quantitative and qualitative analysis. The results of the quantitative analyses are the basis of the qualitative analysis. An example is examining the entity of 'FEAR' and its associations in fake news.

1. Keywords of 'fear' fakeness (generated by the keyness tab for words that are unusually frequent in the fake news but absent in real news). The reference corpus used is the wordlist of Reuter Corpus Volume 1 (RCV1), a corpus of 1.8 million words. RCV1 is an archive of manually categorised newswire stories made available by Reuters Limited for research purposes.

2. Keywords of words related to 'fear' and fear implied phrases (generated by the collocation, clusters, $\mathrm{n}$ grams and KWIC tabs of WordSmith, MonoConc and Collocate 2.0 software) are generated in the form of lexical bundles (Ang \& Tan, 2018).

3. The elicitation of themes based on keyness statistics and concordance data contributes to the qualitative interpretation.

\section{CONCLUSION}

The COVID-19 infodemic has resulted in the widespread dissemination of false medical advice, hoaxes, fake products and fake information about the coronavirus and responses. The findings of this study can empower readers to detect fake news instantaneously without depending on intermediaries. Flooding of misinformation could instil unnecessary fear in people and trigger over-reaction or under-reaction from them. Time is better spent on fighting the virus than fighting fake news. Although the public may not trust information propagated by the media, they may still experience difficulty in resisting influence. Therefore, empowering the public to verify fake news can go a long way in helping people make informed decisions. These notes outline a method through which individuals can be empowered to perform their own detection by looking at the patterns of linguistic use that typifies fake news. 


\section{LANGUAGE USE IN COMPARATIVE APPROACHES TO LIMITING THE EFFECTS OF THE COVID-19 PANDEMIC BY THE GOVERNMENT OF MALAYSIA AND THE UNITED KINGDOM GOVERNMENT (ENGLAND ONLY)}

Peter Woods

\section{INTRODUCTION}

It would appear that widespread infectious disease in a community, epidemics, are part of the human condition. As meat-eaters we have been historically susceptible to virus transmissions from our prey. In 2018, a Swedish tomb was excavated and discovered to harbor evidence of Yersinia pestis within the interred human remains. The estimated date of this individual's death is in a period of European history known as the "Neolithic decline" somewhere between 35003000 BC (Choi, 2018).

A pandemic is defined as "occurring over a wide geographic area and affecting an exceptionally high proportion of the population" (Lexico, n.d.), the first known use of the term being in 1666. Recorded pandemics occurred from at least the $6^{\text {th }}$ century, but the most famous (and documented) was a bubonic plague pandemic, which reached England from mainland Europe in June 1348. It was the first and most severe manifestation of the Second Pandemic, caused by Yersinia pestis bacteria. The term "Black Death" was not used until the late 17th century (Byrne, 2012). The Black Death and subsequent pandemics have all demonstrated an unfortunate ability to reoccur over many years.

For the 2019 pandemic, it is important to clarify that "coronavirus" refers to any virus whose structure presents crownlike spikes. The present virus was given an official name: SARS-CoV-2, and where COVID-19 stands for "coronavirus disease 2019", the name of the disease caused by that virus (WHO, 2020).

\section{PANDEMIC- RELATED TERMS PRECEDING THE COVID-19}

From the $14^{\text {th }}$ century, the idea of isolating the affected individuals, and in the case of the wealthy isolating themselves from the general population, despite lack of knowledge of the cause of the pandemic, was generally accepted. For the fortunate few this was Royal Progress around the country trying to stay one step ahead of the disease, the more unfortunate were walled up in their hovels.

\section{CURFEW}

The term is Middle English and denotes a regulation requiring people to extinguish fires at a fixed hour in the evening: from Old French cuevrefeu, from cuvrir 'to cover' + feu 'fire'. The current sense, to stay indoors between certain hours dates from the late 19th century (Lexico, n.d.).

\section{QUARANTINE}

First known use in the 14th century, from the Latin "quadraginta" and the Italian "quaranta", both meaning " 40 ." Refers to the stopping of ships suspected of having plague on board coming into harbour (possibly Venice) for 40 days (Merriam-Webster Dictionary, n.d).

\section{LOCKDOWN}

Old English "loc" or other Germanic languages "lok", meaning fastener, or secure enclosure, for instance a cell (Sehdev, 2002). 
A "lock-down", $19^{\text {th }}$ century America was a strip of wood or peg that secured a raft together. First used in 1973 in the sense of the confinement of prisoners to their cells for all or most of the day as a temporary security measure (Lexico, n.d.).

\section{SHELTER IN PLACE}

Shelter-in-place or shelter-in-place warning, is instruction to seek safety within the building one already occupies, rather than to evacuate the area or seek a community emergency shelter. Term originated during the Cold War in the 1950 (Yale University, n.d.).

\section{MOVEMENT CONTROL ORDER}

First use appears to be the current pandemic by the Prime Minister of Malaysia, television broadcast $25^{\text {th }}$ March 2020.

\section{PROPOSED STUDY}

PREAMBLE

Both the Government of Malaysia and the UK Government (England) have issued official instructions and advice to citizens since the outbreak of the pandemic. It is clear that language modifiers have been used to exhort and encourage citizens to follow instructions. These have changed over time as restrictions have been lifted in the face of economic consequences. Of particular interest are modifiers related to the overall terms like lockdown or movement control; For example, 'easing' the lockdown and 'recovery' movement control. Using plain language avoids creating barriers that set us apart from the people with whom we are communicating.

\section{DELIMIT}

The source material is restricted to official announcements by Kementerian Kesihatan Malaysia $(\mathrm{MOH})$ and Department of Health and Social Care UK (England only, other nations of UK have their own instructions and advice that differ). Period chosen is from the start of specific instructions given to citizens, late February 2020 (precise date to be confirmed) until 10 June 2020 .

\section{METHOD}

The principal method adopted will be frequency counts of modifier words as a quasi-measure of significance. The official online texts from both governments will be examined for comparative reasons. The daily pronouncements (approximately 100 days) will be aggregated into 14 weekly total texts. The weekly count of high frequency modifiers will be charted over time.

\section{ANALYSIS}

Will concentrate on evolution of preferred modifiers. The analysis will be discursive as the progress of the pandemic moved from safety to a more nuanced consideration of physical health safety, mental health problems and economic turmoil. Of interest are modifiers which could be described as nudge factors. 


\section{COGNITIVE, AFFECTIVE AND CONATIVE MESSAGE STRATEGIES IN OFFICIAL ANNOUNCEMENTS TO EFFECT POSITIVE RESPONSE FOR THE MOVEMENT CONTROL ORDER TO SUPPRESS THE COVID-19 PANDEMIC}

Hazita Azman

\section{BACKGROUND OF STUDY}

In January 2020, when the early endemic signs of the outbreak started in Hubei Province, the Chinese government ordered a lockdown, barring 11 million citizens from going to school or work and closed all commercial establishments except for essential services such as grocers or clinics and hospitals. This was the first severe movement control order issued by a country in an effort to battle the outbreak of the coronavirus. Since then, the virus, identified as COVID19 , has viciously spread at a pandemic rate across the globe. To date in June, WHO has reported over 7.2 million confirmed cases, including more than 413,000 deaths as it spreads at an exponential rate across WHO recognized regions, namely the Americas, Europe, Eastern Mediterranean, South-East Asia, Western Pacific and Africa (WHO Coronavirus Disease Dashboard, June 2020). To decrease the alarming rate of transmission and reproduction of the virus across the population, and in the absence of a COVID-19 vaccine, non-pharmaceutical interventions (NPIs) aimed at reducing contact rates in the population (Ferguson, et.al, 2020, p. 3; Pei, Kandula \& Shaman, 2020) were quickly imposed by affected countries. The NPIs recommended by WHO to governments and public worldwide was to practice hand-hygiene, exercise social distancing, and to stay-in-place. Consequently, most governments adopted this intervention as a policy to mitigate the transmission of the virus by declaring some degree of lockdown state wide or nationwide, and suggesting the notion of a new normal for the immediate future. Obviously the impact of these mandated mitigation policies depends critically on how people respond to their introduction as the interventions are disruptive and entail significant changes in population behaviour and social norms.

\section{PURPOSE OF THE STUDY}

When the notion of a nationwide lockdown was imminent strong public reactions, in many countries, caused panic buying and mass exodus of people attempting to travel back to their hometowns before curfews were imposed. In both the US and Malaysia, similar reactions were reported borne out of fear, confusion, ignorance and misunderstandings about the virus and how it can spread, about the extent of the lockdown and how it will be implemented, as well as about the growing life threatening situation, triggered mainly by the vast amount of misinformation and disinformation on the social media (Azlan, et al, 2020). Clearly, preparing the population to accept the lockdown or stay-in-place and restricted social distancing measures is crucial in ascertaining their safe and effective execution. To this end, how governments communicate about COVID-19 and related situations or conditions should create clarity, build resilience and catalyse positive behavioural change. This study has two related aims. Firstly, it analyses the communication messages imparted by the authorities in the US and Malaysia to their respective citizens to investigate if the following message strategies were employed: the cognitive message strategy to build knowledge, the affective message attributes to manage emotions and the conative message strategy to elicit a desired response. And secondly, based on the content analyses of the messages, conclusions can be made in relation to the impact of the three strategies, if used in the communications, in eliciting desired collective responses, as in accepting the movement control order, in particular. 


\section{THE METHOD}

A qualitative content analysis of primary data source comprising selected official announcements, using the NVIVO-12 software, will be conducted and elements that connote the three types of message intent - cognitive, affective and conative - will be identified and categorized accordingly at the word, sentence, paragraph and overall structure levels. Primary data source for content analysis of these announcements will be collated from the daily briefings conducted by officials from the Ministry of Defence and the Ministry of Health, Malaysia as well as the timed announcements by the Prime Minister of Malaysia between the periods of March until June 2020. Similarly, press briefs by the President of the United States and his team of medical and security advisors between the same periods derived from the televised sessions will be used. Inferences will then be made to compare the extent to which the communications about the interventions conveyed by either country affected responses from their respective citizens. To show this relationship, secondary data from three reliable sources on public's perception and responses to COVID-19 and the intervention policies are corroborated to support these inferences. Specifically, for perspectives on Malaysian public's response to COVID-19, the published nationwide survey on their knowledge, attitude and practices conducted by Azlan, et al (2020) and findings from an unpublished study on public's sentiment analysis about COVID-19 by the Ministry of Health are referred. For similar data on public opinion in the US, a survey conducted by the University of South Florida and Nielsen (2020) will be compared. Limitations of the study with regards data sources will be highlighted where relevant.

\section{SIGNIFICANCE OF THE STUDY}

The findings from the study will put into perspective the importance of designing the three message strategies in conveying official announcements and communications that aim at effecting public acceptance and compliance to emergency policy interventions, especially necessitated by crises such as the pandemic. 


\section{VIRUS IN PARLIAMENT: A CORPUS ANALYSIS OF KEYWORDS RELATED TO PUBLIC HEALTH IN THE MALAYSIAN HANSARD}

Imran Ho Abdullah

\section{INTRODUCTION}

The COVID-19 pandemic has been described by the UNDP as 'the defining global health crisis of our time and the greatest challenge we have faced since World War Two.' (https://www.undp.org/content/undp/ en/home/coronavirus.html). The OECD Economic Outlook June 2020 states the pandemic is 'without precedent in living memory' which 'has triggered the most severe economic recession in nearly a century and is causing enormous damage to people's health, jobs and well-being.' (http://www.oecd.org/economicoutlook/june-2020/) In order to slow the spread of the virus and 'to flatten the curve' so that healthcare system could cope with the number of cases, most governments have initiated months-long lockdown measures or movement control orders which entailed temporary suspending business activity in many sectors and disrupting education and travel.

The seriousness of the pandemic, raises the question as to how our politicians and leaders have addressed public health issues prior to this pandemic. While COVID-19 is new, there have been other threats to public health prior to COVID-19. These include the 1998-1999 Nipah virus outbreak, the 2003-2004 SARS outbreak, the 2007 avian influenza (H5N1) outbreak, the 2009 swine flu (H1N1) outbreak as well as the 2012 Middle East respiratory syndrome coronavirus (MERS-CoV) outbreak. However, none of these outbreaks have been as serious as COVID-19. To this end, the Malaysian Hansard Corpus (MHC), a corpus of Malaysia Hansard transcripts comprising 157 million words spanning five decades can provide insights into how public health issues have been addressed in the Malaysian Parliamentary discourse.

\section{DATA AND METHODOLOGY}

The MHC data utilized in the present study is a specialized corpus of parliamentary data developed by Abdullah, Rahman \& Jaludin (2017). To date, the corpus comprises approximately 157 million words (measured with WordSmith 5.0) from 3,511 parliamentary proceedings obtained from the official portal of Parliament of Malaysia (https://www.parlimen.gov.my/index.php?\&lang=en. The words chosen in the study are kuman (germs), virus and wabak (plague), pandemik, epidemik, jangkitan/infeksi (infection), influenza, demam (fever).

The analysis of the data utilising the frequencies / relative frequencies of the terms and their collocates can be performed. Critical stylistics analysis in the manner suggested by Jeffries \& Walker (2019) can be undertaken to uncover the pattern of use and the discussion of public health issues over the decades.

\section{PRELIMINARY FINDINGS}

Table 1 shows the frequencies and relative frequencies (per million words) of some keywords relating to public health in the Malaysian Hansard Corpus in the $8^{\text {th }}$ Parliament Sitting $\left(3^{\text {rd }}\right.$ December $1990-6^{\text {th }}$ April 1995) up to the $13^{\text {th }}$ Parliament Sitting (24 June $2013-7^{\text {th }}$ April 2018). The frequencies of the words show no particular pattern (i.e becoming more frequent or less frequent over time). For instance, the word wabak (plague) spiked in terms of frequency $(\mathrm{n}=557$; rel. freq $=33.61)$ in the $9^{\text {th }}$ Parliament Sitting (7 June $1995-11$ Nov 1999) coinciding with the epidemic of suspected Japanese encephalitis / Nipah Virus that occurred in Malaysia 
in 1998-1999 among pig farmers. It then declined in frequency to 334 in the $10^{\text {th }}$ Parliament, rising slightly in the $11^{\text {th }}$ Parliament $(n=367)$ and falling to 156 occurences in the $13^{\text {th }}$ Parliament. The same can be observed for the word influenza which hardly occurred in the $8^{\text {th }}$, $9^{\text {th }}$ and $10^{\text {th }}$ Parliament but rose significantly $(n=133$; rel. freq $=5.01)$ in the $11^{\text {th }}$ Parliament (17 May 2004 - 13 Feb 2008) corresponding with the 2004 SARS outbreak and the 2007 avian influenza $(\mathrm{H} 5 \mathrm{~N} 1)$ outbreak. It rose further in terms of frequency $(\mathrm{n}=154$; rel. freq $=5.32)$ in the $12^{\text {th }}$ Parliament (28 April 2008 - 29 November 2012) during the 2009 swine flu (H1N1) outbreak as well as the 2012 Middle East respiratory syndrome coronavirus (MERS-CoV) outbreak. The corresponding frequencies of these words with the different viral outbreaks are also borne out by the collocates of these items.

TABLE 1. Frequency of keywords in the Malaysian Hansard Corpus ( $8^{\text {th }}$ Parliament $-13^{\text {th }}$ Parliament)

\begin{tabular}{|c|c|c|c|c|c|c|c|c|c|c|c|c|}
\hline & \multicolumn{2}{|c|}{$\begin{array}{c}8^{\text {th }} \text { Parliament } \\
\text { Rel. }\end{array}$} & $\begin{array}{l}9^{\text {th }} \mathrm{Pa} \\
\text { Freq }\end{array}$ & $\begin{array}{l}\text { Iment } \\
\text { Rel. } \\
\text { Freq }\end{array}$ & $\begin{array}{c}10^{\text {th }} \mathrm{Pa} \\
\text { Freq }\end{array}$ & $\begin{array}{l}\text { Iment } \\
\text { Rel. } \\
\text { Freq }\end{array}$ & $\begin{array}{l}11^{\text {th }} \mathrm{P} \\
\text { Freq }\end{array}$ & $\begin{array}{c}\text { ament } \\
\text { Rel. } \\
\text { Freq }\end{array}$ & $\begin{array}{c}12^{\text {th }} \mathrm{Pa} \\
\text { Freq }\end{array}$ & $\begin{array}{l}\text { Iment } \\
\text { Rel. } \\
\text { Freq }\end{array}$ & $\begin{array}{l}13^{\text {th }} \mathrm{P} \\
\text { Freq }\end{array}$ & $\begin{array}{c}\text { ament } \\
\text { Rel. } \\
\text { Freq }\end{array}$ \\
\hline bakteria & 13 & 0.73 & 28 & 1.69 & 32 & 1.46 & 52 & 1.96 & 56 & 1.91 & 44 & 1.87 \\
\hline epidemik & 0 & 0.00 & 11 & 0.66 & 3 & 0.14 & 20 & 0.75 & 12 & 0.41 & 9 & 0.38 \\
\hline kuman & 252 & 14.22 & 91 & 5.49 & 83 & 3.79 & 65 & 2.45 & 52 & 1.77 & 58 & 2.46 \\
\hline pandemik & 0 & $\begin{array}{c}0.00 \\
134.0\end{array}$ & 0 & $\begin{array}{c}0.00 \\
118.7\end{array}$ & 0 & $\begin{array}{l}0.00 \\
84.3\end{array}$ & 7 & $\begin{array}{c}0.26 \\
107.2\end{array}$ & 43 & $\begin{array}{l}1.47 \\
71.3\end{array}$ & 0 & $\begin{array}{c}0.00 \\
113.9\end{array}$ \\
\hline penyakit & 2375 & 0 & 1968 & 3 & 1849 & $\begin{array}{c}6 \\
15.6\end{array}$ & 2849 & 5 & 2093 & 9 & 2686 & 1 \\
\hline virus & 165 & 9.31 & 742 & 44.77 & 343 & $\begin{array}{c}5 \\
15.2\end{array}$ & 338 & 12.72 & 207 & 7.06 & 166 & 7.04 \\
\hline wabak & 104 & 5.87 & 557 & 33.61 & 334 & 4 & 367 & 13.82 & 212 & 7.23 & 156 & 6.62 \\
\hline demam & 101 & 5.70 & 88 & 5.31 & 163 & 7.44 & 253 & 9.52 & 156 & 5.32 & 102 & 4.33 \\
\hline infeksi & 3 & 0.17 & 11 & 0.66 & 5 & 0.23 & 4 & 0.15 & 4 & 0.14 & 1 & 0.04 \\
\hline jangkitan & 115 & 6.49 & 145 & 8.75 & 91 & 4.15 & 184 & 6.93 & 166 & 5.66 & 126 & 5.34 \\
\hline influenza & 0 & 0.00 & 4 & 0.24 & 8 & 0.37 & 133 & 5.01 & 154 & 5.25 & 26 & 1.10 \\
\hline
\end{tabular}

\section{FURTHER ANALYSIS}

Further collocational, co-textual patterns and concordance analysis of the keywords as well as a critical stylistics analysis have to be conducted to reveal the underlying principles in the discourse relating to public health. Trends and developments in public health discourse across the various Parliaments can also be studied. 


\section{VIEW FROM MY WINDOW: GLOBAL CONNECTIONS DURING COVID-19}

Ruzy Suliza Hashim

\section{INTRODUCTION}

This paper provides an assessment of a Facebook page called View From My Window. It is a preliminary study of its content; it will take a few more months before extra data is available for a better sustained analysis. For the current available records within the nature of this research note, I provide two snapshots that illustrate lived realities of people in lockdown. Various new pages have sprung on Facebook while Covid-19 rages in many countries. View From My Window is an interesting choice of document to study - it has photos, short narratives of lockdown experiences, and thousands of interactions amongst strangers which use the public space to share some personal and private thoughts of their lives as they grapple with the new normal. For a literary scholar, much of the interactions seem like a long novel of snippets of stories into people's lives. The data will be appealing to students of literature who can compare novels on pandemics such as Daniel Defoe's A Journal of the Plague, Gabriel Garcia Marquez's Love in the Time of Cholera, José de Sousa Saramago's Blindness, Margaret Atwood's Oryx and Crake, Ling Ma's Severance with authentic articulations of communities experiencing similar challenges, in fear for the invisible enemy. Issues involving loss, isolation, friendship, and empathy are particularly highlighted.

\section{CONTEXT}

View from My Window is a group launched by Barbara Duriau on 22 March 2020. On its page, Duriau emphasises the main aim of the group which is to connect people around the world during the pandemic. Due to the virulent nature of coronavirus, many countries instituted lockdown and self-isolation. This was the main strategy that the Chinese government made in the early days of the pandemic in Wuhan which was successful in stopping rapid infection amongst different communities. Lockdowns vary in force; in Wuhan, its citizens were banned from crossing borders; schools, university and non-essential shops were closed; public transport ground to a halt; and only one or two members of a household could go out to make purchases (Langton, 2020). Many people were trapped in their houses for many weeks and months. It is only recently that countries around the globe have begun to relax some of the prohibitions put in place between February to May 2020. The lockdown was crucial in flattening the curve, a term used to ensure hospitals can cope with supply of medicines, hospital attire and equipment, and treatment of patients.

The lockdown means people would have to stay home and stay safe. For most people, the only view they could see during the quarantine within the walls of their home was through the windows of their abode. Hence, Duriau says that "Every day, through our windows, we have the same view." Hence, she proposes each member take a photo, and each person can only send one photo of any of these views that one can see:

\footnotetext{
... the rooftop of your town, overview [of] a park, your tiny garden, buildings, the ocean or a tiny street, share the photo. The idea is for you to share the atmosphere of your daily Life, from BEHIND YOUR WINDOW, where you live during Covid-19 lockdown. https://www.facebook.com/groups/viewfrommywindow.
}

The page became hugely popular (W. Kimball, 2020, N. Chen, 2020). From the time it launched until 11 June 2020, it now has 2, 334,674 members. Currently, there are 350,862 photos. On 29 April 2020, with some countries easing the lockdown, Duriau decided not to accept any new members; no one can now post any photos. Hence, from that day onwards, 
Duriau's team only works on processing pending posts. As of 11 June 2020, there are still 185, 206 photos waiting for approval and eventual uploading. This is an amazing accomplishment because the page has attracted Facebook users from 160 countries within a matter of three months.

\title{
PRELIMINARY DATA ANALYSIS
}

I select two photos that demonstrate the richness of visual presentations, narratives, and responses of members of this group. From a certain window of one's dwelling, the user snaps a particular view of what she sees. Many photos show glorious landscapes of oceans, lakes, rolling hills and mountains, trees, flowers, swimming pools, big gardens and small yards. In the example below, this photo dated 10 June 2020 provides a view of a yard from the living room window. It shows mature trees, nicely-trimmed lawn, and some chairs at the patio.

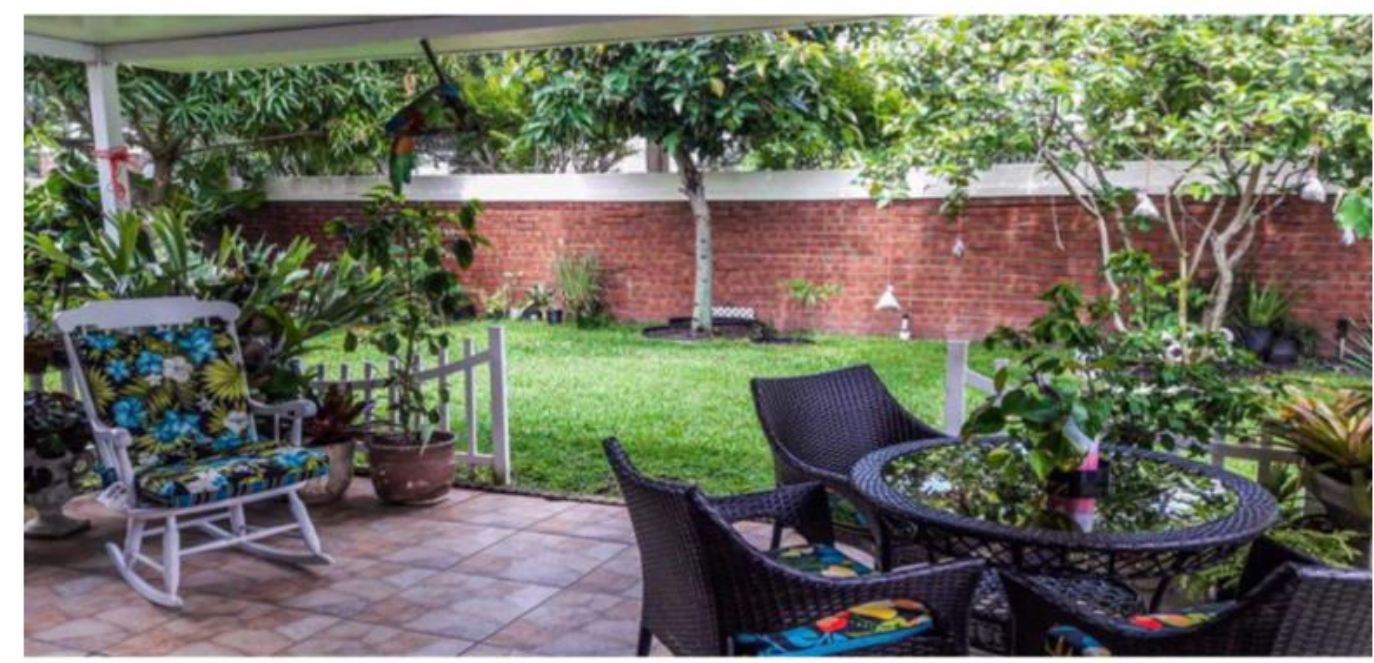

FIGURE 1. Kissimmee, Florida USA, 2.18 pm

The poster from Florida says:

\begin{abstract}
View of our backyard from the living room window - Kissimmee, Florida USA 2:18 pm this afternoon. Hello. I've been enjoying all the wonderful views and the uplifting words the world is sharing via this community. Thank you to the creators of this group for this space.

I've been sheltering in place at home with my parents since March 16 - the day after the Disney parks closed. It's scary how uncertain the future looks, but I have faith we'll get thru this and soon we'll be back to our jobs making magic for our guests.

In the meantime, I'm enjoying my parent's company and the quiet times spent on the patio, the early morning walks and the slow pace of life at the moment.

Please be well, stay safe and healthy. And let me know where you're viewing our pics from.
\end{abstract}

Source: https://www.facebook.com/groups/viewfrommywindow

1000 viewers liked this photo with thumbs-up, love, care, and wow emoticons. It received 854 comments and 15 shares. "And let me know where you're viewing from our pics from" is a refrain that runs through most of the photos posted on the page. Hence, responses such as "So cozy a very nice escape! Blessings from Corpus Christi Texas," "Hopefully it won't be long, that seems a peaceful place to isolate. From Lake Macquarie NSW Australia," "Lovely, relaxing view and glad you are able to enjoy some special times with your parents! Hi from Hilton Head Island, SC. Hoping you will be making magic for guests soon!," "It's great you decided to spend this time with your parents! You have a whole life ahead to be away from them. And some of us wish we had our parents to be with, or our daughters to come now 
to us! Greetings from Cuernavaca, Mexico," "You sound content even if you find this time scary. Thank you for sharing the lovely picture of the porch. Stay safe and hello to your parents! Maryland/USA," "Good that you are with your parents. I live alone and only saw the people who walked by my home if I was outside working in my dooryard. I am now at my summer job doing private duty nursing for a 98 -year-old gentleman. View from the closed French doors. Tenants Harbor Maine." Many more responses provide varying degrees of support and conviviality.

What these different responses convey are messages of hope. It would seem that she is currently not working at Disneyland park and is uncertain when it will open again. She looks forward to the future when she can once more wield magic to Disney visitors. Instead of focusing on the gloom, viewers agree that she is fortunate to be able to enjoy her parents' company; her time there is a much-needed escape. It has been shown that giving social support has well-known benefits for physical and mental health. In a study by Inagaki et al (2016), it is found that giving support advances health by lowering the activity in stress-and threat-related regions of the brain during traumatic experiences. Many of the responses express camaraderie, closeness, and friendship with a person who is a stranger but one that strikes a chord with viewers who perhaps feel the same gratitude of being safe, surrounded by loved ones. Other people are not as lucky. As E. D. Miller (2020) highlights, death is a possibility when infected. Aged parents with underlying diseases are very vulnerable. Photos shared in the group provide brief respite. For some, they are glimpses of happy times.

Another photo, posted by a viewer in Italy, tells another message of optimism:

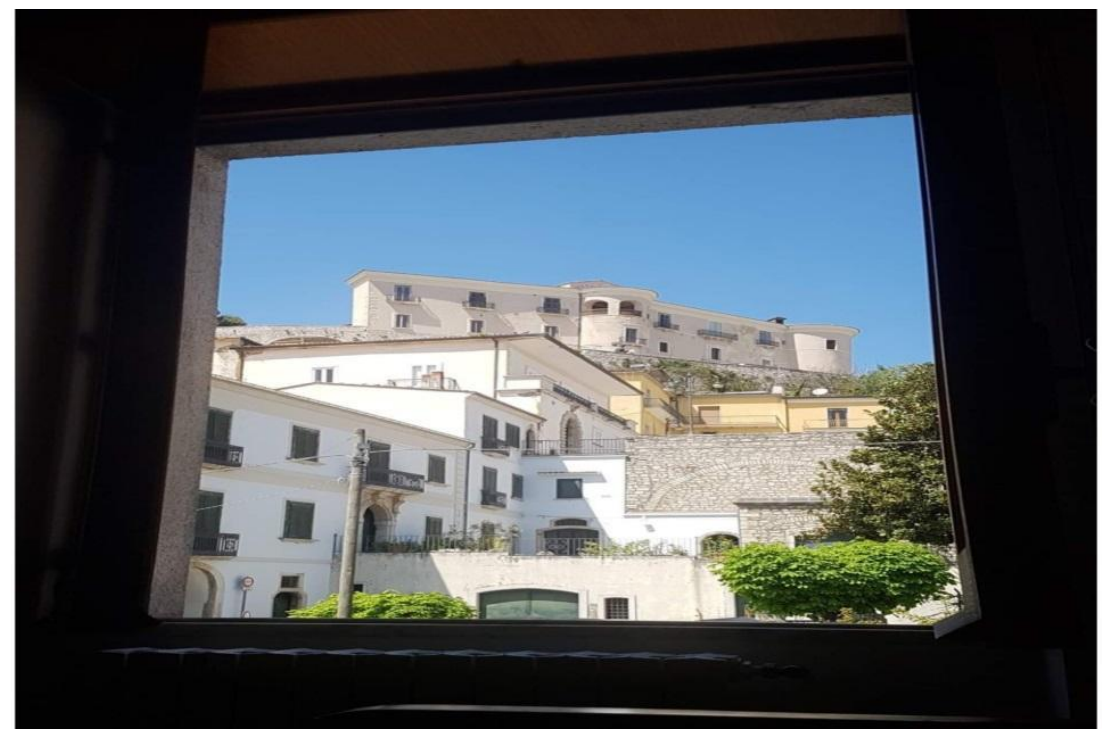

FIGURE 2. Gesualdo / Italy / April 27, 2020 / 1:41pm

\begin{abstract}
My small hometown Gesualdo (Avellino, Campania, Italy) is known for having hosted the prince of musicians Carlo Gesualdo, author of numerous madrigals, who in 1613, being tormented by the untimely death of his son Emanuele, waited to die by locking himself in one of the rooms of his castle. In this time, because of Covid-19, even I am locked down, like everyone else, but I certainly do not give up! Prince Carlo Gesualdo's castle, which is framed by my room window as if it were in a painting, is guarding me, and it is waiting for me to go back out.
\end{abstract}

Source: https://www.facebook.com/groups/viewfrommywindow.

This post had 4500 likes made up of thumbs-up, care, and love emoticons. 795 people commented with 42 shares. This post reveals the poster's anxiety and fear - the story he tells of Carlo Gesualdo hints to a dark possibility of despair. However, unlike Gesualdo, the poster 
will not concede to the virus. His virtual friends offer comforting words "Very picturesque! Yes, you'll be able to escape your isolation soon. Spending thoughts and prayers from Spokane, Washington USA. Stay safe.", "Enjoyed seeing your part of our big beautiful world. Hello from Terrell, Texas. We are partly open now. I appreciate the freedom. Be safe and be blessed." "Good for you! Never give up. Happiness is on its way. Carolina Beach, NC.", "Nice. I'll be right over. Hi from Virginia, USA. My mom was from Sicily. For now, I'll travel through pictures. Thanks for sharing." Many viewers were moved by the story and the artistic framing of the castle.

The lockdown and self-isolation has led to many people feeling trapped without family and friends. Being cut off from human contact can be mentally draining. Italy was one of the first few countries whose health system crumbled in just 24 days. According to one report, doctors had to make very difficult decisions about who could receive care and who had to be denied treatment. For both doctors and patients, "The tragic triage is reminiscent of the choices made on a battlefield, and indeed, Italy is now at war" (R. Mahbubani \& D. Varinsky, 2020). It must have been a scary time for many Italians. The Italian Facebook posting is uplifting; he will win this war.

\section{CONCLUSION}

The pandemic brought a toll on all of us. Whether you are a country known for its first class hospital care or a poor country where its people struggle to make ends meet, the virus is unforgiving. It is this shared fear that triggers emotional responses with the group members of View From My Window. The Facebook has been known to encourage narcissism but in this instance, this group has been described as "the only wholesome social Facebook group on the planet" (Kimball, 2020) and the photos of places around the world at a time when travel is banned and borders are closed, express "joy and solidarity" (Kimball, 2020). As Wiederhold (2020) highlighted in his study, the pandemic has driven people to social media to alleviate their anxiety. These lived realities of people around the world make great teaching resources especially in the literature classroom. Perhaps there is little that separates fact and fiction. 


\title{
COVID-19 AS IT HAPPENS: INSIGHTS FROM LANGUAGE CORPORA
}

\author{
Hajar Abdul Rahim
}

\section{INTRODUCTION}

In recent years, language corpora have become invaluable in fields "such as cross-cultural rhetoric and social psychology... and even economic forecast" (Wilson, Archer and Rayson, 2006: preface). The potential of language corpora and corpus methodology in areas beyond language and linguistics has witnessed the exponential increase in the types and size of corpora developed around the world for various socio-cultural, political and economic research. And access to online texts globally has made it easy for language corpora to be developed for research in current matters that have important social impact. The COVID-19 pandemic is a global concern which has impacted humanity in many ways, and the interest in the language used in reporting, describing, discussing, metaphorizing, and referring to it has motivated the development of language corpora on the pandemic. Two major corpora that are publicly accessible are the Coronavirus Corpus (Mark Davis, 2020) and the Covid-19 corpus (Sketch Engine).

The Coronavirus Corpus, according to Davis (2020), is "designed to be the definitive record of social, cultural, and economic impact of the coronavirus (COVID-19) in 2020 and beyond". Released in May 2020, the corpus comprises texts from online newspapers and magazines in 20 English-speaking countries since January 2020. At the time of the study, the corpus had approximately 350 million words. The Covid-19 corpus made available by Sketch Engine comprises texts that were released as part of the COVID-19 Open Research Dataset (CORD-19). The corpus comprises approximately 280 million words.

\section{OBJECTIVE}

The availability of specialised corpora such as the Coronavirus Corpus and the Covid-19 corpus presents an opportunity for carrying out analyses beyond linguistic and language matters. This is the objective of the current proposal, i.e., to demonstrate how language use changes in tandem with changes and realities in the society. The study is based on an analysis of a selected set of words and phrases that have reached a new level of familiarity for many people since the global outbreak of COVID-19. They are 'virus', 'coronavirus', 'epidemic', 'pandemic', 'new coronavirus', 'novel coronavirus', 'flatten the curve', 'stay at home' and 'work from home'.

The analysis involves the use of the Coronavirus Corpus. While there are many different ways and opportunities to analyse the corpus linguistically, this proposal is interested in the occurrence of the selected set of words in relation to the time of occurrence, particularly when the frequency of each word/phrase peaked. For this purpose, the Coronavirus Corpus frequency tool which provides data on the frequency of words and phrases in 10-day increments from the beginning of January 2020 was used. The data generated can be likened to a diachronic overview of the use of the expressions over a limited span of time, in this case approximately 6 months (early January to June 2020), related to the COVID-19 global context.

\section{DATA ANALYSIS}

The total frequency of the terms and the frequency of each one in relation to the time when the occurrence peaked are presented in the table below. 
TABLE 2. Frequency of occurrence in relation to time in the Coronavirus Corpus

\begin{tabular}{|c|c|c|c|c|}
\hline \multirow[t]{2}{*}{ Expression } & \multirow[t]{2}{*}{ Total frequency } & \multicolumn{3}{|c|}{ Peaked } \\
\hline & & Frequency & Per million & Time \\
\hline virus & 466958 & 14837 & $3,114.95$ & $1^{\text {st }}$ week Feb 2020 \\
\hline coronavirus & 1036403 & 23548 & $4,943.78$ & $1^{\text {st }}$ week Feb 2020 \\
\hline new coronavirus & 48605 & 1725 & 362.15 & $1^{\text {st }}$ week Feb 2020 \\
\hline novel coronavirus & 65867 & 3407 & 715.28 & $1^{\text {st }}$ week Feb 2020 \\
\hline epidemic & 46852 & 2757 & 688.83 & $2^{\text {nd }}$ week Feb 2020 \\
\hline pandemic & 493869 & 52454 & $1,720.64$ & $2^{\text {nd }}$ week May 2020 \\
\hline flatten the curve & 5559 & 1494 & 26.90 & $3^{\text {rd }}$ week March 2020 \\
\hline stay at home & 23662 & 7286 & 131.21 & $3^{\text {rd }}$ week March 2020 \\
\hline work from home & 16748 & 2167 & 80.81 & $2^{\text {nd }}$ week March 2020 \\
\hline
\end{tabular}

The data on when each term peaked mirrors the changes that took place around the world, reflecting the impact of the COVID-19 outbreak on language use. For instance, the terms 'new coronavirus' and 'novel coronavirus' which peaked at the beginning of February consistently declined in frequency from the beginning of March. This trend shows that at this juncture as more had been discovered about the virus, the focus of discussions and reports began to shift. One of the emerging issues then is the spread of the disease. At this point the term 'epidemic' which peaked in the first week of February began to be replaced by the word 'pandemic'. Interestingly, the frequency of 'pandemic' is more than 10 times than the frequency of 'epidemic' in total, although the term 'pandemic' did not show up in the corpus until mid-March when the World Health Organisation (WHO) declared that COVID-19 a pandemic. The term 'pandemic' began to spike at 1,258.05 per million words by the third week of March and peaked, as shown in the table in the second week of May. The announcement of COVID-19 as a pandemic immediately saw many countries going into lockdown and the phrases 'flatten the curve', 'stay at home' and 'work from home' began to emerge, apart from other terms such as 'quarantine', 'panic buying', 'vaccine', 'social distancing', 'mask', 'frontliners', 'unemployment', 'donations' and many other equally important and interesting terms. The phrase 'flatten the curve' began to increase in use as the cases of COVID-19 rose in early March, and peaked mid-March. Around the same time, the phrases 'stay at home' and 'work from home' became household terms. As the former applies to everyone, it seems only logical that its frequency is much higher than the latter. The phrase 'stay at home' peaked one week after 'work from home' as it needed to be drummed into the public.

The emergence and use of the terms, as exemplified above, reflect the change that took place over the course of the last few months. This analysis presents a micro view of how language reflects social realities. Corpora such as the Coronavirus Corpus (Davis, 2020) as well as Covid-19 Corpus (Sketch Engine, 2020) can be used to analyse a multitude of linguistic as well as social, cultural, economic and political issues, based on language patterns and use. 


\section{AFTER CALAMITY: DUALITY AND CO-SIGNIFIERS}

Mohd Muzhafar Idrus

\section{INTRODUCTION}

My own turn to what I call duality and co-signifiers draw from an intention to construct concrete bridge between (re)directing attention to objects and the ways of how these doubly bearings impact contemporary illnesses. Its motivation is to dismantle texts, making visible conjecture and discontinuities in texts, between knowing and establishing new meanings in analyzing calamities post- COVID-19. Yet, because to know what it means growing up postCOVID-19 at varying levels somehow requires deliberate intention, it demands elaborations that (dis)entangle the complex webs of bearings in unofficial accounts. At this end, I offer a method that springs from a combination of concepts drawn from literary works and philosophical criticisms to recontextualize constructions of (re)orientation to generate insights into intense responses at chaotic, often disruptive circumstances of COVID-19. I firstly begin by contextualizing these two broad frameworks. I then describe my approach of duality and co-signifiers. Of central importance is the ways of how duality and co-signifiers are shaped by dynamic relations of interpretation, perception, and orientation. By incorporating these two lenses, we will be able to (dis)engage ourselves with (un)familiar signifiers at personal visions.

\section{TEXTS, CONCEPTS, AND METHODS}

My contribution on duality-in-perception firstly interweaves Sara Ahmed's notion of (re)orientation. The force behind Sara Ahmed's (2006) phenomenology comes from the need to move away from a one-directional analysis to analyzing "those objects" that "take us in a certain direction" (p.542). The integral insight in excavating issues that hook them up to broader affiliations such as society, community, identity, and history is not a natural progression; instead, they move in varying and often complex ways, as "the world that is 'around' has already taken certain shapes, as the very form of what is more and less familiar" (p. 545). This, Ahmed (2006) summarizes, involves two central ideas of (re)orientation: (re)directing focus and repetitions. The former, (re)directing our focus, not only forces us to confront issues that are obvious, but also those that lie implicitly. The latter, repetitions of labor, generates pointers about what objects are (re)circulated and to what ways these (re)circulations direct one's attention. As some "objects" are "being directed toward some objects and not others," (Ahmed, 2006, p. 546), one must ask, "who faces" these issues? Does the problem "point toward some bodies rather than others," why? (Ahmed, 2006, p. 547). The notion of (re) orientation goes beyond preliminary stage of documenting texts and contexts by not only necessarily focusing on explicit objects, but also analyzing "how orientations involve 'more than 'one' of an encounter" (Ahmed, 2006, p. 551). I argue that Sarah Ahmed's contention speaks directly to the question of duality, of not only focusing on the presence, construction, and engagement of COVID-19, but also its absence, deconstruction, and disengagements that can do justice to texts concerning illnesses, instead of merely attempting to shoehorn contemporary illness (COVID-19) into one/a single prescribed overarching framework. This duality of introspection and retrospection, rebuts rehearsed meanings of what it means growing up post- COVID 19 and disattaches one from (over)familiarity with COVID19. Duality ignores (pre)conceived arguments and counter critiques what exists 'behind' of what we know and 'forecast' the future of these texts. By combining the notion of duality into literary analysis, literary scholars look 'backward' and 'forward' across stories of illnesses. For example, texts elaborating COVID-19 that are associated with war veterans, famines, human trafficking, under-represented communities, homelessness, individuals with post-traumatic 
stress disorder, including issues such as ethics, at-risk personhood, home/host/diasporic families, and borderland security could (re)clarify how human beings respond to calamities, disasters, and maladies.

My second agenda to incorporate co-signifiers is inspired from Jennifer Schucci's autobiographical literary criticisms. Schucci draws our attention to this method which refers to personal narratives that can cultivate, reflect, and create positive changes within our lives (Schucchi, 2015, p. 4). Personal narratives, according to Schucci, can be especially empowering for literary scholars because the combination of reader response, textual analysis, and personal narratives contributes to the observation that in order for contemporary plights to be heard, it must speak to diagnose and problematize causality, coherence, closure, and thoughts. This tendency to render voices at deep, personal levels makes autobiographical literary criticisms an ideal concept to use. Autobiographical literary criticisms, while carrying a modicum of risk (of narratives being deeply planted in the subconscious), generates "power of the personal within literary scholarship and within individual lives" (Scucchi, 2015, p. 6). Such an orientation of autobiographical criticisms has clear affinities with what I now call cosignifiers. Co-signifiers build better bridges between personal narratives and the signification of problems, of common sense and sufferings, of mundane everyday habits and everyday experience (Idrus, Hashim, and Mydin, 2016, 2020). These signifiers, while playing instrumental roles in daily experiences, can generate intense emotions, snaking into the minds of readers, altering what we know thus far and what we know anew about illnesses such as COVID-19. Personal narratives that are read through a one-page narrative, a combination of hashtags, letters to presidents / editors, and memoirs make visible various cultural, sociopolitical, neoliberal, moral, and empathetic co-signifiers across unofficial accounts of COVID-19. They push not only choices and consequences concerning COVID-19, but also replenish thoughts and processes by which one understands COVID-19. By analyzing cosignifiers across personal narratives of contemporary illnesses, we are able to dislodge wellworn points and arrive at perspectives that are less shaped by hatred, conflict, and fear.

\section{CONCLUSION}

Duality and co-signifiers work to destabilize the unity of contemporary illnesses's texts. A representation of calamity, their consequences to readers, and profound emotions working their ways to literary works is a product of how attention is mobilized and shifted. To look through the incorporated lenses of duality and co-signifiers is to describe rather than to prescribe narratives, ignoring the pressure of the institutional context in which stories concerning COVID-19 exist. Meanings and interpretation of sufferings, disappointments, and chaos that shape what and how stories are read across COVID-19 contexts operate within the circles of duality and co-signifiers. By employing duality and co-signifiers, the depth and dialogic nature of COVID-19 conversations can be brought back to the center so that they no longer live under a predetermined, 'hegemony-based' frame. 


\section{DISCOVERING COVID-RELATED NEOLOGISMS FOR LEXICOGRAPHY}

Robert Lew \& Iztok Kosem

\section{INTRODUCTION}

Linguistics and various related disciplines cannot ignore the fact that the production of language in this short period has been overwhelmingly COVID-19 centred. This has been the case for standard and non-standard language varieties, represented by news media and social media respectively. An example of this are extraordinary updates with COVID-19-related vocabulary of dictionaries such as the Oxford English Dictionary and Merriam Webster Dictionary, published much more quickly than the usual update intervals would dictate.

\section{NEWS CORPORA}

In order to be able to detect such changes in language, one needs access to a so-called monitor corpus, which would be continuously updated with daily language production. An example of such a corpus is the Timestamped JSI web corpus (Trampuš \& Novak 2004), which harvests up to 150,000 news articles from 75,000 RSS feeds every day. The corpus (https://www.sketchengine.eu/jozef-stefan-institute-newsfeed-corpus) contains articles from over 35 languages, and 18 of those language corpora can also be found in the Sketch Engine corpus tool (Kilgarriff et al, 2004).

Such a corpus offers several possibilities for linguistic analysis, from detecting new words (lexical neologisms) to identifying new senses (semantic neologisms) or usages of existing words. The identification of lexical neologisms is generally easier and there are many special tools available (e.g. Cartier, 2019) to help linguists with this task. Also, many corpus tools can produce a list of keywords (see Figure 3), i.e. words (or sequences of words) that are more typical (or exclusive) for a corpus of a certain time period compared with another, reference, corpus. Nonetheless, even after obtaining such a list, one still faces a fair amount of manual inspection of the items on the list and their concordances. This is needed because lexical neologisms can be hidden away among other rare lemmas such as misspellings, text conversion errors, and tokenisation, lemmatisation or tagging errors. Items with just a few hits in the reference corpus need to be scrutinized as well: they may have been classified as misspellings or otherwise ignored in the past.

Even more challenging is the identification of new senses or uses of existing words, as they tend to be less frequent than existing senses. Keyword lists are also a potential point of departure for such analysis, as they can point to words with significant increase in usage in recent years, as implemented in Sketch Engine's Trends. Yet, much more informative in such cases is the context, e.g. collocations. One possible approach is to divide a corpus into different diachronic subcorpora, and compare the collocational behaviour of the word using the Sketch Difference functionality of Sketch Engine. Here, we split the Timestamped JSI web corpus, into two subcorpora: 2013-2019 and 2020-half (up to June). The analysis of the modifiers of the noun lockdown (one of the words with a significant increase in usage in 2020) shows that, prior to 2020, lockdowns were shorter and limited to smaller areas as opposed to lockdowns during the COVID-19 pandemic (Figure 4). Moreover, such comparisons can even provide geolocational information of COVID-19-related usage, for example the grammatical relation lockdown in reveals nouns such as Wuhan, Luzon, Hubei, Lombardy, and Italy in 2020 (but not in 2013-2019). A similar analysis of collocations, but by comparing computer-mediated language with the reference corpus, has been conducted by Pollak et al. (2019). 


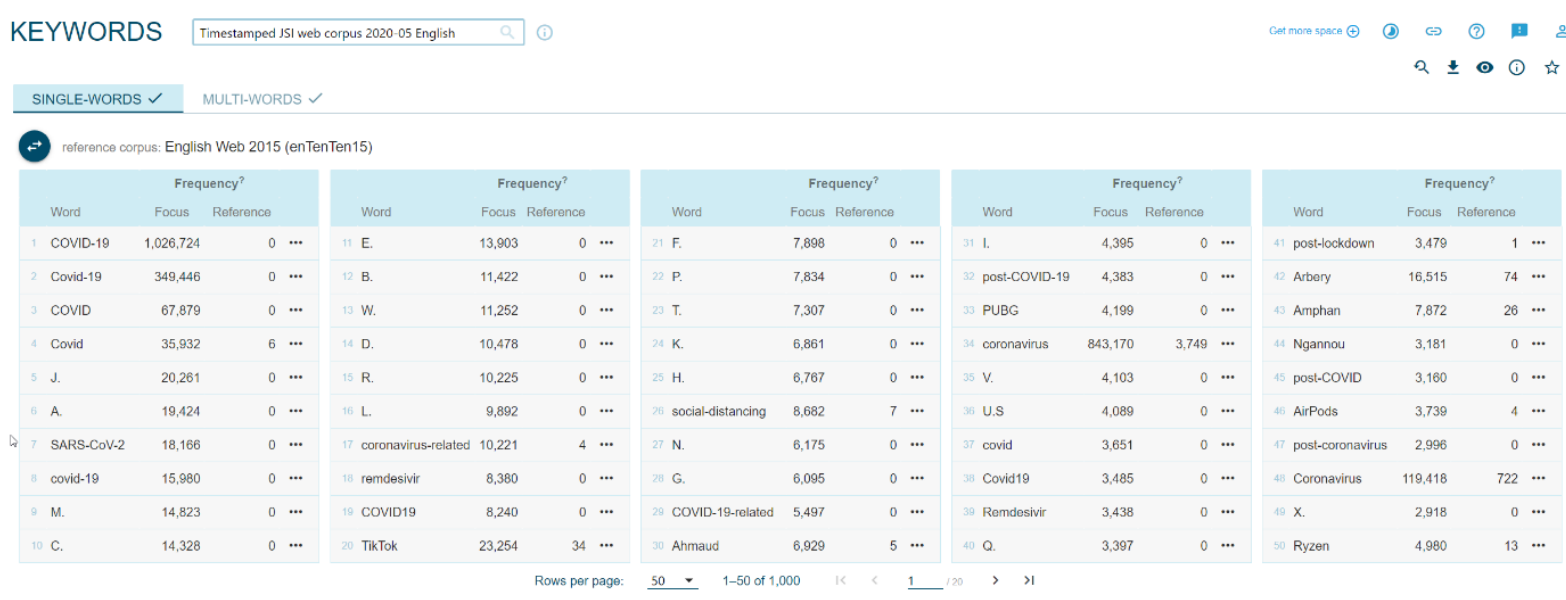

FIGURE 3. Top 50 lemmas that were frequent in Timestamped JSI web corpus (May 2020) and rare or not found in the English Web 2015 corpus (source: Sketch Engine)

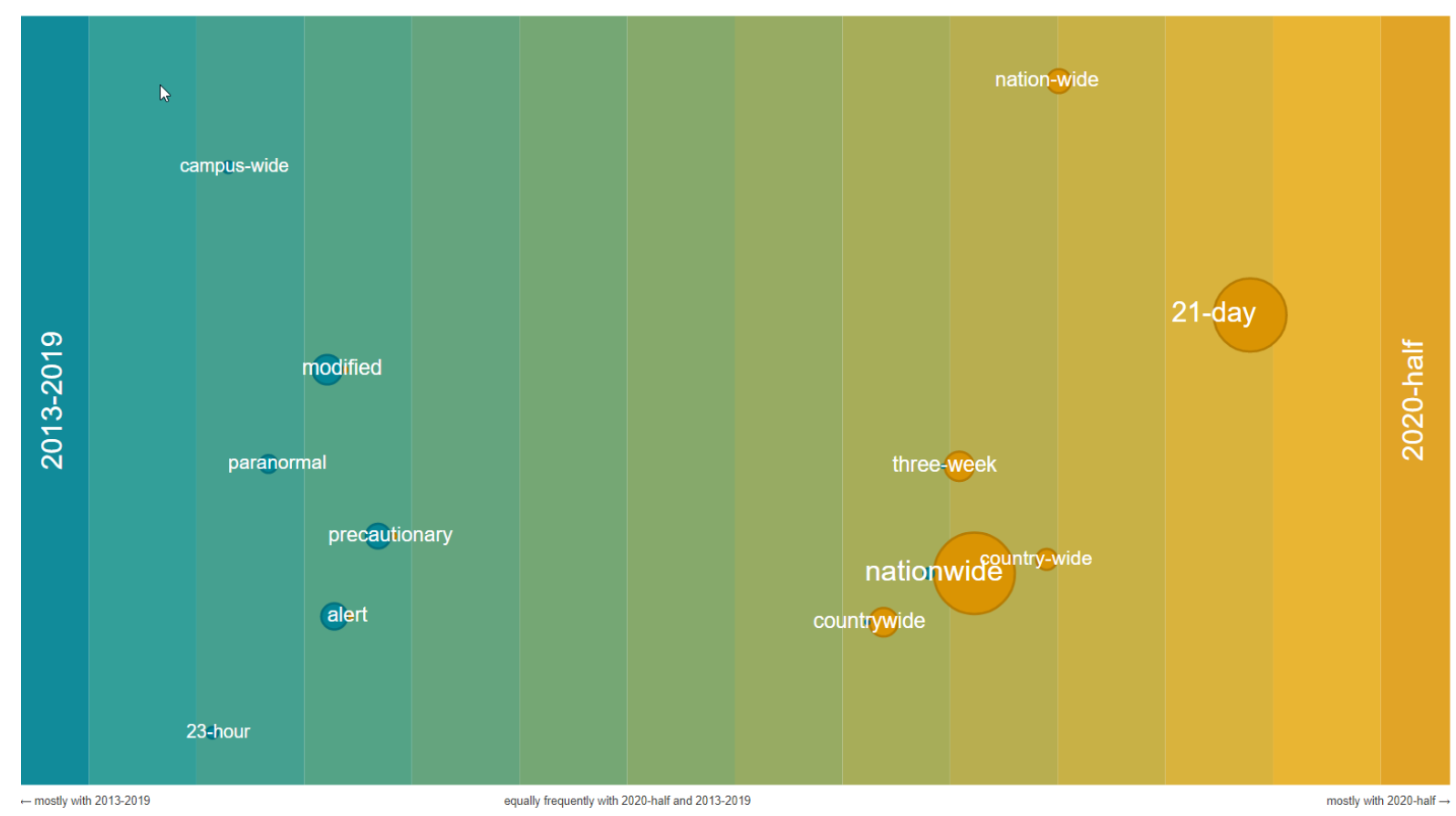

FIGURE 4. Collocates of lockdown in two subcorpora of Timestamped JSI web corpus

\section{SOCIAL MEDIA}

Another approach to detecting new senses or usages of existing words by looking at context is distributional semantics. For example, Cook et al. (2013) used a word sense induction approach to identify different senses of the word, and reported good results on fleshing out new and not so frequent senses. Similarly, Fišer and Ljubešić (2019) used word embeddings to detect semantic shifts between usage of words in the reference corpus of Slovene and a corpus of Slovene tweets.

In fact, social media such as Twitter, Facebook, etc. and other types of computermediated communication such as forums and blogs have become particularly relevant in the time of COVID-19, as in the absence of physical access to media or face-to-face communication, more and more people have used these channels to voice their opinions on matters related to COVID-19. There is a body of research studying the correlation between tweets and outbreaks of epidemic diseases (Achrekar et al. 2011; Broniatowski et al. 2013; 
Diaz-Aviles \& Stewart 2012), showing that posts on Twitter can even be used to predict outbreaks. There are already a few similar small-scale studies on COVID-19 (e.g. Lopez et al. 2020; Jahanbin \& Rahmanian 2020); however, the analyses conducted are less detailed and are based on corpora compiled using key search terms such as covid-19 and virus. One problem of using corpora compiled in such a manner (a similar method was used by Mark Davies to compile The Coronavirus Corpus) is that the data is highly biased toward a particular topic; consequently, one cannot be sure how dominant a particular topic is in a particular medium. Moreover, the list of search terms can never be complete, and runs into the circularity problem of trying to collect a corpus to analyse a certain new topic by list words one thinks identify that very topic.

However, the linguistic view of computer-mediated communication is bound to be somewhat biased anyway, especially as far as social media are concerned, since Facebook and Instagram do not allow their data to be harvested. Further problems for analyses are caused by the non-standard nature of computer-mediated language, for example intentional misspellings, distortion of language patterns such as the use of hashtag with the nominative even when the text requires another case form (especially problematic in morphologically rich languages), etc. All this leads to errors in corpus annotation procedures (tokenisation, lemmatisation, part-ofspeech tagging). A possible fix is the use of annotation tools trained on non-standard language, but these are not available for all languages and are in general less reliable than annotation tools for standard languages.

\section{OVERVIEW OF ALL SECTIONS}

COVID-19 has had a significant impact on our lives, and the way we communicate. Standard and computer-mediated language have felt this impact and the studies of both are needed. Also, the interaction between the two deserves attention, as it would be interesting to analyse public reactions to media announcements related to COVID-19 measures, such as to help public bodies improve the clarity of their messages, or address potential issues in measures proposed or announced. The fact that the pandemic has had such a profound effect on the entire world means that cross-lingual analyses of this phenomenon can also be conducted, to answer questions such as whether new words or usages of words have also entered the language where the outbreak was much less serious.

The scholars have led the discussion and ideation of several areas of study, ranging from linguistic pattern analyses to document analyses. Some of the studies have presented preliminary findings while the rest will continue to draw data for analysis. Despite basing their arguments on a similar issue that is COVID-19 and how the pandemic affects the world in addition to public health, the scholars postulate different research methods for analysis and many interesting facets departing from the central theme.

What is valuable from the current and prospective findings is the nature of the insights which are not derived from a single source but from worldwide corpora or official documents by several governments. The data are analysed and some are contextualised for comparative purposes, resulting in a veritable channel to understand how different governments handle issues related to the theme and what we can learn from them subsequently. The findings comprise a twofold insight - one that describes and one that guides. Studies that describe help us to learn about human language at a personal level as well as the effective strategies executed by different governments; the studies that guide help writers, research novices, and authorities in particular fields by revealing structures of moves at a governmental level for further discourse analysis studies. Therefore, the present and prospective findings are expected to benefit stakeholders as the insights will help inform a) praxis by providing a rich source and plethora of anecdotes for teaching and learning, particularly in literature classrooms, b) 
research by sharing results of different research methods and paradigms and creating the possibility of future research in other aspects, and c) policy by examining current official documents and providing a pathway for extensive discourse analysis.

\section{ACKNOWLEDGEMENTS}

This work was supported by the Research Fund provided by FRGS/1/2018/SS09/UKM/02/1.

\section{NOTES}

FEAR in COVID-19 Fake News: A corpus-based approach - Assoc Prof Dr Tan Kim Hua (Centre for Research in Languages and Linguistics, Faculty of Social Sciences \& Humanities, Universiti Kebangsaan Malaysia drtankimhua@gmail.com, https://tankimhua.wordpress.com/

Language Use in Comparative approaches to limiting the effects of the Covid-19 pandemic by the Government of Malaysia and the United Kingdom Government (England only) - Prof Dr. Peter Woods (Knowledge Management Centre, Faculty of Creative Multimedia, Multimedia University, Malaysia) p.woods@mmu.edu.my

Cognitive, Affective and Conative Message Strategies in Official Announcements to Effect Positive Response for the Movement Control Order to Suppress the COVID-19 Pandemic - Prof Dr. Hazita Azman (Centre for Research in Languages and Linguistics, Universiti Kebangsaan Malaysia) hazita@ukm.edu.my

Virus in Parliament: A corpus analysis of keywords related to public health in the Malaysian Hansard - Prof Dato' Dr Imran Ho Abdullah (Centre for Research in Languages and Linguistics, Universiti Kebangsaan Malaysia), imranho@ukm.edu.my

View From My Window: Global Connections During Covid-19 - Prof Datin Dr. Ruzy Suliza Hashim (Centre for Research in Languages and Linguistics, Universiti Kebangsaan Malaysia), ruzy@ukm.edu.my

COVID-19 as it happens: insights from language corpora - Prof Dr. Hajar Abdul Rahim (School of Humanities, Universiti Sains Malaysia), hajar@usm.my

After calamity: Duality and co-signifiers - Dr. Mohd Muzhafar Idrus (Faculty of Major Language Studies, Universiti Sains Islam Malaysia) muzhafaridrus@usim.edu.my

Article Editor - Dr. Nur Ehsan Mohd Said - Faculty of Education, Universiti Kebangsaan Malaysia, nurehsan@ukm.edu.my

Discovering COVID-related Neologisms for Lexicography - Prof Dr. Robert Lew (Faculty of English, Adam Mickiewicz University, Poznań, Poland) \& Iztok Kosem (Jožef Stefan Institute \& University of Ljubljana, Slovenia), rlew@amu.edu.pl, iztok.kosem@ijs.si

\section{REFERENCES}

Abdullah, I. H., Rahman, A. N. C. A., \& Jaludin, A. (2017). The Malaysian Hansard Corpus. Culturomics Workshop UKM. 27 April 2017.

Achrekar, H., Gandhe, A., Lazarus, R., Yu, S.H., \& Liu, B. (2011). Predicting flu trends using Twitter data In IEEE Conference on Computer Communications Workshops (INFOCOM WKSHPS), Shanghai (pp. 702707). doi: 10.1109/INFCOMW.2011.5928903. 
Ahmed, S. (2006). Orientations: Toward a queer phenomenology. GLQ: A Journal of Lesbian and Gay Studies, 12(4), 543-574.

Ang, L. H., \& Tan, K. H. (2018). Specificity in English for Academic Purposes (EAP): A Corpus Analysis of Lexical Bundles in Academic Writing. 3L The Southeast Asian Journal of English Language Studies, 24(2), 82-94. doi: 10.17576/31-2018-2402-07.

Ang, L. H., \& Tan, K. H., He, M. (2017). A corpus-based collocational analysis of noun premodification types in academic writing. 3L The Southeast Asian Journal of English Language Studies, Vol 23(1): 115 - 131. http://doi.org/10.17576/3L-2017-2301-09

Azlan, A. A., Hamzah, M. R., Sern, T. J., Ayub, S. H., \& Mohamad, E. (2020). Public knowledge, attitudes and practices towards COVID-19: A cross-sectional study in Malaysia. PLoS ONE, 15(5): e0233668. Retrieved from https://doi.org/10.1371/journal.pone.0233668

Broniatowski, D. A., Paul, M. J., \& Dredze, M. (2013). National and local influenza surveillance through Twitter: An analysis of the 2012-2013 influenza epidemic. PLoS One. 8(12): e83672. doi: 10.1371/journal.pone.0083672.

Byrne, J. P. (2012). Encyclopedia of the Black Death. Santa Barbara, CA: ABC-CLIO. p. xxi. ISBN 9781598842531.

Cartier, E. (2019). Neoveille, web platform for finding and monitoring neologisms in monitor corpora. Neologica. $13,23-54$.

Chen, N. (2020). View From My Window. Columbia Broadcasting System (CBS).

Retrieved from https://miami.cbslocal.com/video/4578396-view-from-mywindow/?fbclid=IwAR3or0JPGePZCM1r0jdAICShP5gFu5H4EQjUuK

Choi, C. J. (2018). Ancient, Unknown Strain of Plague Found in 5,000-Year-Old Tomb in Sweden. Retrieved from https://www.livescience.com/64246-ancient-plague-swedish-tomb.html

Cook, P., Lau, J. H., Rundell, M., McCarthy, D., \& Baldwin, T. (2013). A lexicographic appraisal of an automatic approach for detecting new word senses'. In Kosem, I., J. Kallas, P. Gantar, S. Krek, M. Langemets and M. Tuulik (Eds.), Electronic lexicography in the 21 st century: Thinking outside the paper. Proceedings of eLex 2011 (pp. 49-65), Ljubljana; Tallinn: Trojina, Institute for Applied Slovene Studies; Eesti Keele Instituut. . Retrieved from http://eki.ee/elex2013/proceedings/eLex2013 04_Cook+etal.pdf.

Corpus analysis of the language of Covid-19. (2020). Retrieved from https://public.oed.com/blog/corpus-analysisof-the-language-of-covid-19/

Davis, M. (2020). The Coronavirus Corpus. Retrieved from https://www.english-corpora.org/corona/

Diaz-Aviles, E., \& Stewart, A. (2012). Tracking Twitter for epidemic intelligence: Case study: EHEC/HUS outbreak in Germany, 2011. In Proceedings of the 4th Annual ACM Web Science Conference (WebSci '12) (pp. 82-85) New York: Association for Computing Machinery. doi: 10.1145/2380718.2380730.

Ferguson, N. M., Laydon, D., Nedjati-Gilani, G., et al. (2020) Impact of non-pharmaceutical interventions (NPIs) to reduce COVID-19 mortality and healthcare demand. Imperial College London. Retrieved from https://doi.org/10.25561/77482

Fišer, D., \& Ljubešić, N. (2019), Distributional modelling for semantic shift detection. International Journal of Lexicography 32(2), 163-183, doi: 10.1093/ij1/ecy011.

Hua, J., \& Shaw, R. (2020). Corona Virus (COVID-19) "Infodemic" and Emerging Issues through a Data Lens: the Case of China. International Journal of Environmental Research and Public Health, 1-12

Idrus, M. M., Hashim, R. S., \& Mydin, R. M. (2017). Rediscovery of the Malay 'local': Youth and TV fiction in Malaysia. International Journal of Adolescence and Youth, 22(2), 210-225. doi: https://doi.org/10.1080/02673843.2016.1154876

Idrus, M. M., Hashim, R. S., \& Mydin, R. M. (2020). Postcolonial civic identity and youth (dis)organizing environment: A growth into citizenship analysis. GEMA Online Journal of Language Studies, 20(2), 133-147. doi: http://doi.org/10.17576/gema-2020-2002-08

Inagaki, T. K., Bryne, H. K. E., Suzuki, S., Jevtic, I., Hornstein, E. Bower, J. E., \& Eisenberger, N. I. (2016). The Neurobiology of Giving Versus Receiving Support. Psychosomatic Medicine. DOI: $10.1097 / \mathrm{PSY} .0000000000000302$

Jahanbin, K., \& Rahmanian, V. (2020). Using Twitter and web news mining to predict COVID-19 outbreak. Asian Pacific Journal of Tropical Medicine 2020, 1-3. doi: 10.4103/1995-7645.279651.

Jeffries, L., \& Walker, B. (2017). Keywords in the Press: The New Labour Years. London: Bloomsbury

Jeffries, L., \& Walker, B. (2019). Austerity in the Commons: A corpus critical analysis of 'austerity' and its surrounding grammatical context in Hansard (1803-2015). In K. Power, T. Ali, \& E. Lebdušková (Eds.), Discourse Analysis and Austerity: Critical Studies from Economics and Linguistics (pp. 53 - 80) Oxford: Routledge, Taylor \& Francis Group.

Kilgarriff, A., Rychlý, P., Smrž P., \& Tugwell, D. (2004). The Sketch Engine. In Williams G. \& S. Vessier (Eds.), Proceedings of the Eleventh EURALEX International Congress, EURALEX 2004, Lorient, France, July 
6-10, 2004 (pp. 105-116). Lorient: Faculté des Lettres et des Sciences Humaines, Université de Bretagne Sud.

Kimball, W. (2020). "View From My Window" Is the Last Good Group on Facebook. Gizmodo. 24 April. Retrieved from https://gizmodo.com/view-from-my-window-is-the-last-good-group-on-faceboo1843042911. Accessed 11 June 2020.

Langton, K. (2020). China lockdown: How long was China on lockdown? Express. 30 May. Retrieved from https://www.express.co.uk/travel/articles/1257717/china-lockdown-how-long-was-china-lockdowntimeframe-wuhan

Lexico. (n.d.) Retrieved from https://www.lexico.com/en/definition/lockdown

Lexico, (n.d.) Retrieved from https://www.lexico.com/en/definition/pandemic

Lopez, C. E., Vasu, M., \& Gallemore, C. (2020). Understanding the perception of COVID-19 policies by mining a multilanguage Twitter dataset. Retrieved from https://arxiv.org/abs/2003.10359.

Mahbubani, R., \& Varinsky, D. (2020). How Italy spiralled from a perfectly healthy country to near collapse in 24 days as the coronavirus took hold. Business Insider. March 14. Retrieved from https://www.businessinsider.com/italy-falling-apart-coronavirus-pandemic-doctors-tough-choices2020-3. Accessed 11 June 2020.

Merriam-Webster Dictionary. (n.d.) Retrieved from https://www.merriam-webster.com/dictionary/lockdown

Mertens, G., Gerritsen, L., Duijndam, S., Salemink, E., \& Engelhard, I. (2020, April 2). Fear of the coronavirus (COVID-19): Predictors in an online study conducted in March 2020. PsyArXiv, 2 Apr. 2020. Web. https://doi.org/10.1016/j.janxdis.2020.102258

Miller, E. D. (2020) The COVID-19 Pandemic Crisis: The Loss and Trauma Event of Our Time. Journal of Loss and Trauma. DOI: 10.1080/15325024.2020.1759217

Nor, N. F., Rahman, A. M., Jaluddin, A., \& Abdullah, I. H., \& Tiun, S. (2019). A Corpus Driven Analysis of Representations Around the Word 'ekonomi' in Malaysian Hansard Corpus. Gema Online Journal of Language Studies, 19(4), 66-95. DOI:http://doi.org/10.17576/gema-2019-1904-04

Pei, S., Kandula, S., \& Shaman, J. (2020) Differential effects of intervention timing on COVID-19 spread in the United States. Department of Environmental Health Sciences, Mailman School of Public Health, Columbia University. Paper in collection COVID-19 SARS-CoV-2 preprints from medRxiv and bioRxiv. Retrieved from https://doi.org/10.1101/2020.05.15.20103655

Pollak, S., Gantar, P., \& Holdt, S. A. (2019). What's new on the internetz? Extraction and lexical categorisation of collocations in Computer-Mediated Slovene. International Journal of Lexicography, 32(2), 184-206. doi: 10.1093/ij1/ecy026.

Sault, S. (2020). Why lockdowns can halt the spread of COVID-19. World Economic Forum. Geneva. https://www.weforum.org/agenda/2020/03/why-lockdowns-work-epidemics-coronavirus-covid19/

Scucchi, J. (2015). A place for the personal: Autobiographical literary criticism through the lens of transformative learning [Unpublished master's thesis]. Utah State University, Logan, Utah, United States of America.

Sketch Engine (2020). Corpus-19 Corpus. Retrieved from https://www.sketchengine.eu/covid19/

Social change and linguistic change: the language of Covid-19. (2020). Retrieved from https://public.oed.com/blog/ the-language-of-covid-19/

Trampuš, M., \& Novak, B. (2012). The internals of an aggregated web news feed. In Proceedings of 15th Multiconference on Information Society 2012 (IS-2012) (pp. 221-224).

University of South Florida-Nielsen. (2020). Sunshine state survey on public opinion on COVID-19 response. University of South Florida. Pp. 1-13. May 13, 2020.

View From My Window. (2020). $\quad$ Facebook. $\quad$ Retrieved from https://www.facebook.com/groups/viewfrommywindow. Accessed 11 June 2020.

WHO Coronavirus Disease Dashboard. (2020). Retrieved from https://covid19. who.int/

WHO. (2020, March 11). World Health Organisation announces Covid-19 outbreak a pandemic [Press release]. Retrieved from www.euro, who.int>health-topics

Wiederhold, B. K. (2020). Using Social Media to Our Advantage: Alleviating Anxiety During a Pandemic. Cyberpsychology, Behavior, and Social Networking. Volume 23: Number 4. pp. 197-198.

Wilson, A., Archer, D., \& Rayson, P. (2006). Corpus linguistics around the world. Amsterdam: Rodopi.

Yale University. (n.d.) Emergency Management. Retrieved from https://emergency.yale.edu/be-prepared/shelterplace 